\title{
Cardiovascular Parameters in Chronic Haemodialysis Patients in Tobago
}

\author{
R Alfred-Demas, B Moore, A Trim, A Sandy-Robinson, A Wasunna
}

\begin{abstract}
Objective: To identify cardiac risk factors that contribute to sudden cardiac death in a haemodialysis population and thus optimize them, in an effort to minimize death in this population.

Methods: This was a retrospective study and audit. The medical records of the patients receiving chronic haemodialysis were reviewed for the period January to December 2014. Data collected included age, gender, comorbidities, types of access, length of time on haemodialysis, laboratory indices, and main electrocardiographic and echocardiographic findings.

Results: All patients had elevated intact parathyroid hormone. Some patients had hypocalcaemia, hyperphosphataemia and mild anaemia. Prominent echocardiographic findings were left ventricular hypertrophy and pulmonary hypertension.

Conclusion: Sudden cardiac death in end-stage renal disease patients on haemodialysis may be predicted by certain abnormal laboratory findings and echocardiographic findings which may all be positively correlated.
\end{abstract}

Keywords: Cardiovascular, echocardiogram, haemodialysis patients

\section{Parámetros cardiovasculares en pacientes con hemodiálisis crónica en Tobago}

\author{
R Alfred-Demas, B Moore, A Trim, A Sandy-Robinson, A Wasunna
}

\begin{abstract}
RESUMEN
Objetivo: Identificar los factores de riesgo cardiaco que contribuyen a la muerte cardiaca súbita en una población de hemodiálisis, y de este modo optimizarlos, en un esfuerzo por minimizar los fallecimientos por tal motivo en esta población.

Métodos: Se trata de un estudio retrospectivo y auditoría. Se revisaron las historias clínicas de los pacientes que recibían hemodiálisis crónica, correspondientes al periodo de enero a diciembre de 2014. Los datos recogidos incluyeron edad, sexo, comorbilidades, tipos de acceso, tiempo de hemodiálisis, indices de laboratorio, y los principales hallazgos electrocardiográficos y ecocardiográficos.

Resultados: Todos los pacientes tenían hormona paratiroides intacta elevada. Algunos pacientes tenían hipocalcemia, hiperfosfatemia y anemia leve. Los resultados ecocardiográficos más sobresalientes fueron la hipertrofia ventricular izquierda y la hipertensión pulmonar. Conclusión: La muerte cardiaca repentina en pacientes con la enfermedad renal en fase terminal sujetos a hemodiálisis, puede predecirse por ciertos resultados de laboratorio anormales y los resultados de la ecocardiografia, todos los cuales se pueden correlacionar positivamente.
\end{abstract}

Palabras clave: Cardiovascular, ecocardiograma, hemodiálisis

From: Department of Internal Medicine, Scarborough General Hospital, Tobago, Scarborough, Trinidad and Tobago, West Indies.

West Indian Med J 2018; 67 (2): 157
Correspondence: Dr R Alfred-Demas, Department of Internal Medicine, Scarborough General Hospital, Connector Road, Signal Hill, Tobago, Scarborough, Trinidad and Tobago, West Indies. Email: ralfreddemas.trha@gmail.com 


\section{INTRODUCTION}

Cardiovascular risk factors are a significant burden in patients with end-stage renal disease receiving haemodialysis, and most patients die from cardiovascular-related causes. Sudden cardiac death outside of coronary artery disease (CAD) is the most common aetiology (1). Even after angioplasty, patients still have sudden cardiac death which may suggest that obstructive CAD may not be a significant factor. Fatal ventricular arrhythmias may be the leading cause of sudden cardiac death in patients with end-stage renal disease receiving chronic haemodialysis (2).

As such, it is important to identify cardiac risk factors that contribute to sudden cardiac death and thus optimize them, in an effort to minimize death in a haemodialysis population.

\section{SUBJECTS AND METHODS}

This was a retrospective study and audit. The medical records of the patients receiving chronic haemodialysis were reviewed for the period January to December 2014. These patients were approved by the renal ethics committee of the Scarborough General Hospital, Tobago, Trinidad and Tobago, for haemodialysis. Patients who received only emergency haemodialysis and were not approved by the renal ethics committee for long-term dialysis were excluded from the audit.

Data collected included age, gender, co-morbidities, types of access, length of time on haemodialysis, laboratory indices, and main electrocardiographic and echocardiographic findings.

The study was approved by the Medical Chief of Staff of the Scarborough General Hospital.

\section{RESULTS}

Of the 58 patients receiving chronic haemodialysis in Tobago, data were found for 52 patients for the period January to December 2014. There were nine deaths recorded during this period. The ages of the patients studied ranged from 17 to 73 years, with an average age of 50 years. Most of these patients represented the productive working population. Sixty per cent of the patients were male.

All $(100 \%)$ of the patients were hypertensive, and $57 \%$ of them had diabetes mellitus. Other co-morbidities were hepatitis $\mathrm{C}$, human immunodeficiency virus (HIV), autosomal dominant polycystic kidney disease, trauma, and congenital anomaly of the kidneys.

Patients received chronic haemodialysis via an arteriovenous fistulae in $62 \%$ of the cases and via permanent catheters in $30 \%$ of the cases, with grafts accounting for $8 \%$ of the cases. The length of time on haemodialysis ranged from one month to seven years, with an average of two to three years.

All $(100 \%)$ of the patients who were able to urinate had proteinuria. All patients had elevated intact parathyroid hormone. Laboratory values are demonstrated in the Table. Some patients had hypocalcaemia, hyperphosphataemia and mild anaemia.

Table: Average pre-dialysis laboratory values of patients

\begin{tabular}{ll}
\hline Parameter & Result (range) \\
\hline Corrected calcium (serum) & $8.4 \mathrm{mg} / \mathrm{dL}(8.6-10.2)$ \\
Serum albumin & $3.6 \mathrm{~g} / \mathrm{dL}(3.5-5.2)$ \\
Serum phosphorus & $5.3 \mathrm{mg} / \mathrm{dL}(2.7-4.5)$ \\
Blood urea nitrogen & $61 \mathrm{mg} / \mathrm{dL}(6-23)$ \\
Serum creatinine & $11.4 \mathrm{mg} / \mathrm{dL}(0.7-1.2)$ \\
Low-density lipid & $90 \mathrm{mg} / \mathrm{dL}(<100)$ \\
Intact parathyroid hormone & $1246 \mathrm{pg} / \mathrm{ml}(10-55)$ \\
Haemoglobin & $9.5 \mathrm{~g} / \mathrm{dL}(>10)$ \\
\hline
\end{tabular}

All patients had an electrocardiogram. Their electrocardiograms revealed that most of them were in sinus rhythm. Only two patients had atrial fibrillation detected by electrocardiogram.

Of the patients studied, $77 \%$ had their echocardiograms done. Left ventricular hypertrophy (in $67 \%$ of the patients) and left atrial enlargement (60\%) were most commonly demonstrated. Right ventricular systolic pressure was $45 \mathrm{mmHg}$ on average, with $47 \%$ of the patients exhibiting pulmonary hypertension. Valve abnormalities included mitral regurgitation (25\%), tricuspid regurgitation $(25 \%)$, aortic insufficiency $(<1 \%)$, as well as calcification of cardiac valves (12\%). Eight per cent of the patients had wall motion changes indicative of ischaemic heart disease. Effusions were noted in the pericardium $(8 \%)$ and in the pleura $(7 \%)$ of patients.

Nine patients died during the year when data were collected (January to December 2014). The cause of death was mostly sudden cardiac death. There were two cases of sepsis and one case of acute myocardial infarction. Four of these nine persons managed to have an echocardiogram before death, and they all had left ventricular hypertrophy and diastolic dysfunction and preserved systolic function.

\section{DISCUSSION}

Cardiovascular complications are the main cause of death in patients with chronic kidney disease (CKD) undergoing haemodialysis therapy (3). The cardiovascular 
mortality in these individuals is 10 - to 20 -fold more frequent than in the general population (3). Despite underlying co-morbidities, the traditional risk factors for cardiovascular disease do not completely explain this excess risk, which seems to be influenced by the socalled non-traditional risk factors associated with CKD. These latter factors accelerate the course of CAD and are associated with a higher prevalence of ventricular hypertrophy, myocardial fibrosis, valvulopathies, arrhythmias and sudden death (3).

The cardiomyopathy of the patient undergoing dialysis can be due to the presence of ischaemic heart disease and morphological alterations of the left ventricle in response to pressure and volume overload, as well as anaemia (4).

The physiopathology of the transformations induced by uraemia in the left ventricular chamber is complex and multifactorial. Hyperparathyroidism can also contribute to myocardial fibrosis, and this, along with left ventricular hypertrophy, can cause diastolic dysfunction (5). Shifts in electrolytes and fluid balances can cause arrhythmias and sudden cardiac death. Diabetic autonomic neuropathy and hypertensive heart disease are also contributing factors (6). Fluid overload contributes to venous congestion (7). Long-term haemodialysis via arteriovenous access may be involved in the pathogenesis of pulmonary hypertension by affecting pulmonary vascular resistance and cardiac output (8). Left-sided heart disease also causes pulmonary hypertension.

Changes in cardiac structure and function detected by echocardiography are common in patients with CKD undergoing haemodialysis, and have been recognized as key outcome predictors. This is non-invasive, and left ventricular findings remain constant despite fluid shifts and pre- and post-dialysis status.

Blood investigations such as blood tests, urea, creatinine and potassium are influenced by volume status, pre- and post-dialysis status, as well as diurnal changes (9). Functional assessments also have to be done both at baseline and during dialysis. Structural changes (such as left ventricular hypertrophy) can be assessed at any point in time, hence the value of echocardiograms in this population. An electrocardiogram demonstrates left ventricular hypertrophy much later than an echocardiogram would. An ambulatory electrocardiogram may pick up arrhythmias. Other interesting parameters include heart rate volume and measuring baroreceptor changes.

Whatever parameters are investigated and documented, protocols should be in place in a dialysis unit geared at detecting early the risk of sudden cardiac death so that intervention or early cardiology follow-up or further investigations should be instituted for such patients so as to prolong life.

\section{CONCLUSION}

Sudden cardiac death in end-stage renal disease patients on haemodialysis may be predicted by certain abnormal laboratory findings and echocardiographic findings which may all be positively correlated.

These include derangements in calcium, phosphorus, intact parathyroid hormone and haemoglobin and left ventricular hypertrophy, which is picked up early on an echocardiogram. As such, it may be useful to monitor these findings in such patients, and early intervention should be introduced in order to prolong life.

\section{REFERENCES}

1. Collins AJ, Foley RN, Herzog C, Chavers B, Gilbertson D, Ishani A et al. United States Renal Data System 2008 Annual Data Report. Am J Kidney Dis 2009; 53(1 Suppl): S1-374.

2. Herzog CA. Sudden cardiac death and acute myocardial infarction in dialysis patients: perspectives of a cardiologist. Semin Nephrol 2005; 25: 363-6.

3. Barberato SH, Pecoits-Filho R. Echocardiographic alterations in patients with chronic kidney failure undergoing hemodialysis. Arq Bras Cardiol 2010; 94: 140-6.

4. Ikram H, Lynn KL, Bailey RR, Little PJ. Cardiovascular changes in chronic hemodialysis patients. Kidney Int 1983; 24: 371-6.

5. Krishnan AV, Kiernan MC. Uremic neuropathy: clinical features and new pathophysiological insights. Muscle Nerve 2007; 35: 273-90.

6. HEMO Study Group. Cardiac diseases in maintenance haemodialysis patients: results of the HEMO study. Kidney Int 2004; 65: 2380-9.

7. Ganda A, Weiner SD, Chudasama NL, Valeri AM, Jadoon A, Shimbo D et al. Echocardiographic changes following hemodialysis initiation in patients with advanced chronic kidney disease and symptomatic heart failure with reduced ejection fraction. Clin Nephrol 2012; 77: 366-75.

8. Yigla M, Nakhoul F, Sabag A, Tov N, Gorevich B, Abassi Z et al. Pulmonary hypertension in patients with end-stage renal disease. Chest 2003; 123: 1577-82.

9. Saravanan P. Advances in arrhythmia and electrophysiology. Risk assessment for sudden cardiac death in dialysis patients. Circulation: Arrhythmia and Electrophysiology 2010; 3: 553-9. 